\title{
EVALUATION OF TREATMENT METHODS AND CLINICAL CHARACTERISTICS OF PATIENTS APPLYING TO THE OUTPATIENT CLINIC WITH COMPLAINT OF MASTALGIA
}

\author{
Şener Bahçe Zeynep, Aktaş Hamza
}

${ }^{1}$ Private Memorial's Hospital Clinical of General Surgery, Diyarbakır, Turkey.

${ }^{2}$ Private Memorial's Hospital Clinical of Dermatology, Diyarbakır, Turkey.

\section{$\bar{A} \bar{B} \overline{S T} \mathbf{R} \bar{A} \bar{C} \mathbf{T}$}

Objective: Mastalgia or breast pain is one of the most vital complaints among women patients. This study aims to determine the prevalence of mastalgia and the properties of pain, elucidate the associated factors, particularly modifiable ones, and establish a treatment of standard. Methods: The study evaluated 685 female patients admitted to our outpatient clinic with a complaint of mastalgia in the period between 2017 and 2019. Results: Mean age of the patients was $35.20 \pm 10.28(13-86)$. The pain was experienced in the right breast of $123(17.9 \%)$ patients, in the left breast of $141(20.6 \%)$ patients, and in both breasts of $422(61.5 \%)$ patients. The mean pain value was found to be 5.29. The study population comprised $61(8.9 \%)$ patients in the menopause state, whereas $624(91.1 \%)$ patients were not in menopause. The pain was noncyclic in $519(75.8 \%)$ patients, while cyclic for $166(24.2 \%)$ patients. For treatment, a restricted diet in terms of coffee, salt, and fat as well as wearing supportive bra were recommended for $456(66.5 \%)$ patients, while 181 patients with pain VAS (Visual Analog Scale) score of 8 and above was initiated with vitex agnus-castus. No patient was initiated with local or systemic analgesics and LHRH (luteinizing hormone-releasing hormone) analogs. Conclusion: The prevention and management of mastalgia reflected that restricted salt intake, regulated diet, and the use of properly fitted bras could significantly improve the quality of life. Appropriate radiological imaging could eliminate patients' concerns regarding developing cancer.

Keywords: Breast cancer, Diet, Mastalgia, Risk factor.

\section{Corresponding Author:}

Hamza Aktaş, MD.

Address: Private Memorial Hospital. Firat Bulvarı. Peyas Mah. No: 12. 21080 Kayapınar/Diyarbakır.

E-mail: drhamzaaktas21@ gmail.com

ORCID ID: 0000-0003-3610-500X

Tel: $+(90) 0505$ 5025109; Fax: 04123146666

Copyright @ 2012- 2021 Dr H. Aktaş et al. This is an open access article published under Creative Commons Attribution -Non Commercial- No Derives 4.0 International Public License (CC BY-NC-ND). This license allows others to download the articles and share them with others as long as they credit you, but they can't change them in any way or use them commercially.

***** Published in 2021

doi: 10.46327/msrjg.1.000000000000201

doi url: https://doi.org/10.46327/msrig.1.000000000000201

\section{INTRODUCTION}

Mastalgia is defined as tension, discomfort, and pain associated with one or both of the breasts [1]. The pain tends to be bilateral and often felt in the upper, outer quadrant of the breast [2]. Approximately 60$70 \%$ of women have this complaint at least once in their lifetimes, and of whom, 10-20\% experience the pain severely [3-5]. Apart from impairing their daily quality of life, breast pain also causes women to worry over whether or not they have breast cancer [4]. Mastalgia could originate from breast tissue itself, extra-mammary tissues, or psychological reasons. The predisposing factors of mastalgia include macromastia, diet or lifestyle changes, hormone replacement therapy (HRT), ductal ectasia, mastitis, increased water and salt retention, and highdose caffeine intake [1].

Mastalgias are classified as cyclical and noncyclical. Cyclic mastalgia affects women between the ages of 30 and 40, initiating during the two weeks leading up to the onset of the menses, then easing up afterward, and reappearing with the onset of the next menstrual cycle. Increased estrogen, decreased progesterone levels, increased prolactin are found to be associated with the pain formation of mastalgia. Caffeine, high fat diet, and iodine deficiency also contribute to the causes of cyclic pain. Cyclical mastalgia pain spontaneously resolves in $22 \%$ of patients, whereas treatment is required for $65 \%$ of the patients $[6,7]$. 


\section{Research Article}

Journal of Medical and Surgical Research

JMSR 2021 Vol. VIII, n 1: 984- 989

Non cyclic pain is usually unilateral and localized to a particular quadrant of the breast. Although it is frequently encountered in the $40 \mathrm{~s}, 10-15 \%$ of patients experience it after the age of 50 , and it is often observed in the perimenopausal period [8]. Noncyclic mastalgia constitutes approximately $25 \%$ of patients experiencing breast pain. Differential diagnosis revealed the common causes of chest wall pain include costochondritis (Tietze's disease), nerve root pain as in cervical spondylitis, and herpes zoster. Non-chest wall pain can result from diverse causes such as ischemic heart disease, biliary pain, and peptic ulcer. Traumatic fat necrosis of the breast tissue, Mondor's disease, diabetic mastopathy, tumor, cyst, mastitis can also contribute to the onset of mastalgia $[8,9]$. The present study aimed to evaluate the demographic characteristics, etiological causes, and treatment approaches of patients who attended our outpatient clinic with complaints of mastalgia.

\section{MATERIALS AND METHODS}

We retrospectively evaluated 685 women who visited our outpatient clinic with breast pain between May 2017 and January 2020. Inclusion criteria for this study involved patients who complained of breast pain for the first time. Patients who were diagnosed with breast cancer and Idiopathic Granulomatous Mastitis (IGM) and Fibroadenoma following biopsy, and patients who had pains induced by pathologies out of the breast tissue (costochondritis, nerve root pain as in cervical spondylitis, and herpes zoster) and had incomplete information in their files were excluded from this study. Age, family history, menopausal status, presence/absence of hormone replacement therapy
(HRT), and the comorbidities of the cases, as well as the type of mastalgia (cyclic or noncyclic), were evaluated. Imaging methods were performed within the indication. Breast biopsy was administered radiologically in suspicious lesions such as BIRADS 4 or 5, solid lesions that were palpable during breast examinations of women, under the age of 35 years, in the presence of micro- calcifications requiring radiologically biopsy, patients having lobulation in the mass, and patients with suspected IGM. The data were recorded on the mastalgia evaluation form. The VAS pain scale helped to assess the severity of pain. The patients with and without pathological findings were categorized separately based on the examination of breasts.

Patients with VAS value under 8 were recommended diet and use of post-surgery bras. However, vitex agnus-castus was prescribed in addition to diet and use of post-surgery bras for the patients whose VAS values were 8 and above. Furthermore, antibiotherapy and steroid therapy were planned for the other patients according to their indications.

The data obtained were statistically analyzed using the software program SPSS 22.0. Continuous variables were expressed as mean \pm standard deviation, whereas variables indicated by count were represented as percentages. Chi-square tests were employed for comparisons. The local ethics committee confirmed that formal approval was not required for this retrospective audit of practice.

\section{RESULTS}

The mean age of 685 patients in the study was found to be $35.20 \pm 10.28$. The study population comprised $486(70.9 \%)$ patients below the age of 40 years, while $199(29.1 \%)$ were above 40 years (Table I).

Table I. Demographic differences of the cases

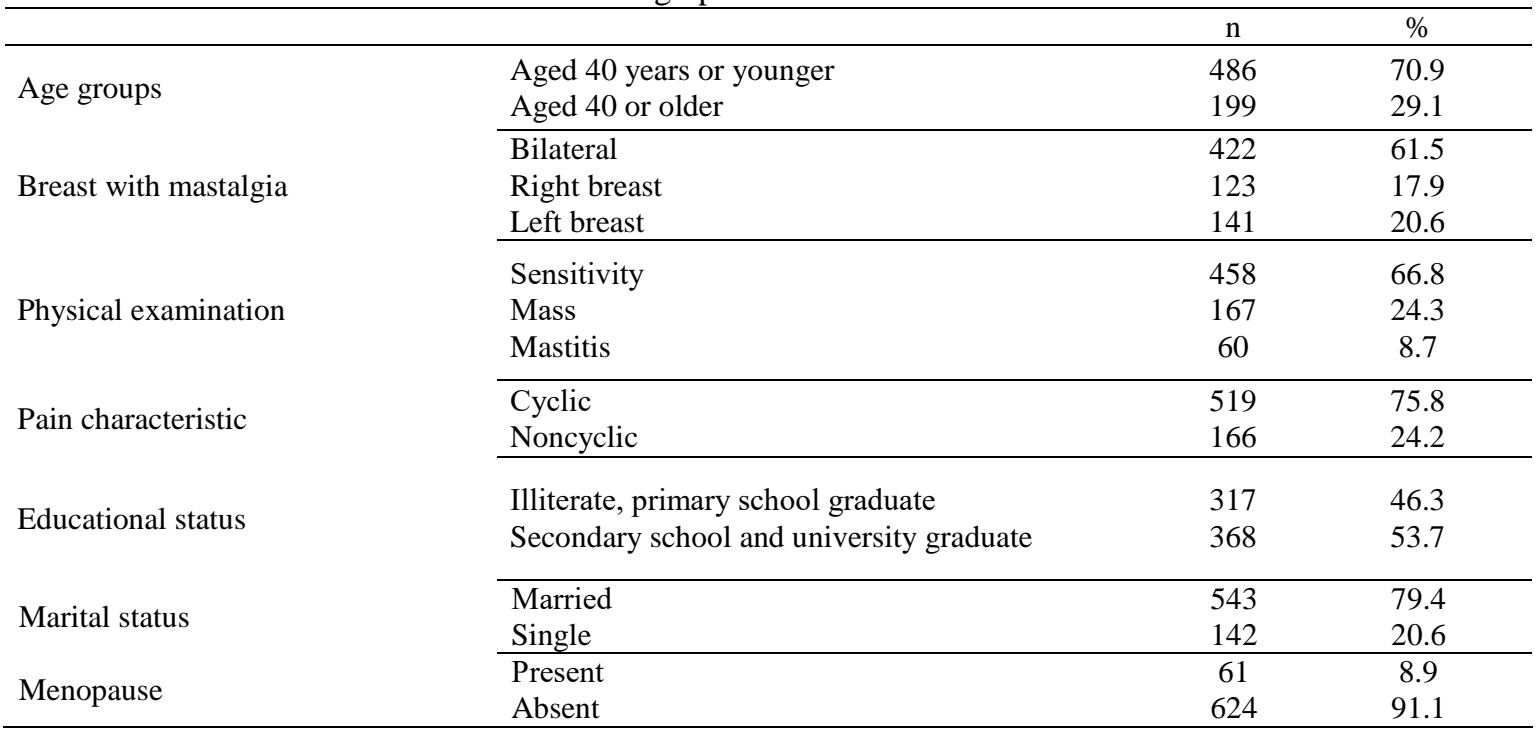




\section{Research Article}

Journal of Medical and Surgical Research

JMSR 2021 Vol. VIII, n 1: 984- 989

Records revealed $61(8.9 \%)$ patients were in menopause, and $624(91.1 \%)$ patients were not in menopause. The age of their first menarche was 13 years for $190(27.7 \%)$ patients, 12 years for 169 (24.7\%) patients, and 14 years for 114 (16.6\%) patients. Oral contraceptives (OCS) were taken by $534(77.9 \%)$ patients, while 151 (22.1\%) patients received OCS.

The pain was experienced in the right breast of 123 $(17.9 \%)$ patients, in the left breast of $141(20.6 \%)$ patients, and in both breasts of $422(61.5 \%)$ patients. The mean pain score of the patients was 5.29 . The pain scores were in the range of $0-4$ (mild) for $39.7 \%$ of the study participants, 5-7 (moderate) for $35.8 \%$, and $8-10$ (severe) for $24.5 \%$ of the study subjects. Of the patients, $20.6 \%$ were single, and $79.4 \%$ were married. T-test analysis reported higher pain scores in the case of the married people, and the difference was found to be statistically significant between married and single women $(\mathrm{p}=0.05)$.

There was no family history of breast cancer in 561 $(81.9 \%)$ of the patients. However, $34(5 \%)$ recorded history of breast cancer in their first-degree relatives and $91(13.3 \%)$ in their second-degree relatives. The educational status of the partakers highlighted that $317(46.3 \%)$ of the patients were illiterate or primary school graduates, $368(53.7 \%)$ were secondary school or university graduates.

Out of all women who visited our outpatient clinic with any complaints, $23 \%$ suffered from breast pain. Physical examination revealed 458 (66.9\%) patients had tenderness, 167 (24.4\%) had mass, and 60 $(8.8 \%)$ had mastitis. Biopsy was performed in 67 $(9.8 \%)$ of the patients. All patients with the complaint of mastalgia were examined by ultrasonography (USG); however, $21 \%$ of patients underwent mammography. The pain was found to be noncyclic in 519 patients $(75.8 \%)$ and cyclic in 166 patients $(24.2 \%)$. No abnormality was recorded from the USG findings of $485(70.8 \%)$ patients (Table 2$)$. On the other hand, cyst was detected in 74 (10.8\%) patients, mastitis in 48 (7\%) patients, fibroadenoma in $43(6.3 \%)$ patients, ductal ectasia in $17(2.5 \%)$ patients, tumor in $8(1.2 \%)$ patients, and accessory breast in $9(1.3 \%)$ patients (Figure 1,2,3,4). While $518(75.6 \%)$ patients reported no use of nicotine, 167 $(24.4 \%)$ patients were using nicotine.
Table II. Ultrasonography findings

\begin{tabular}{lcc}
\hline & $\mathbf{n}$ & $\mathbf{\%}$ \\
\hline Normal & 485 & 70.8 \\
Cyst & 74 & 10.8 \\
Fibroadenoma & 43 & 6.3 \\
Ductal dilatation & 17 & 2.5 \\
Solid lesion & 8 & 1.2 \\
Infection & 13 & 1.9 \\
Granulomatous mastitis & 35 & 5.1 \\
Accessory breast & 9 & 1.3 \\
Other & 1 & 0.1 \\
\hline
\end{tabular}

For treatment (Table III), 456 (66.5\%) patients were recommended a restricted diet in terms of coffee, salt, and fat as well as wearing a supportive bra, while vitex agnus-castus was initiated in 181 (26.4\%) patients with pain VAS score of 8 and above apart from recommended dietary change and wearing a supportive bra.

Table III. Treatment modality of patients

\begin{tabular}{lcc}
\hline & n & $\%$ \\
\hline Dietary change + supportive bra & 456 & 66.5 \\
Vitex-agnus-castus + dietary change + supportive bra & 181 & 26.4 \\
Steroids, antibiotics & 48 & 7 \\
\hline
\end{tabular}

Positive response to treatment was witnessed among $403(88.3 \%)$ out of 456 patients who were recommended a diet and supportive bra only. On the other hand, $126(69.1 \%)$ of the patients receiving diet plus medical treatment stated that they benefited from the treatment. Systemic steroids were prescribed to 35 patients diagnosed with granulomatous mastitis by biopsy. Based on their antibiogram results, 13 patients with bacterial mastitis were started antibiotic and non-steroidal anti-inflammatory treatment. Appropriate treatments were also initiated for the patients who were diagnosed with fibroadenoma, ductal ectasia, tumor, intra- ductal papilloma, and accessory breast, and their treatment process was followed. No patient was treated with local analgesics and LHRH analogs. 


\section{Research Article}

Journal of Medical and Surgical Research

JMSR 2021 Vol. VIII, n 1: 984- 989

\section{DISCUSSION}

Mastalgia or breast pain is one of the most significant complaints of general surgery outpatient clinics $[10,11]$. Mastalgia is a chronic problem affecting physical and social activity, work-school activities, and sexual activity and could last for years [10]. Apart from disrupting a women's daily life quality, breast pain is also a cause of concern for women regarding breast carcinoma. This is attributed to the increased incidence of breast cancer based on the technological advances in screening methods and imaging techniques $[1,12]$. Breast cancer is the most predominant form of malignancy in women worldwide, the primary objective is to relieve the pain and improve the quality of life as well as to exclude the diagnosis of cancer in women with mastalgia following current examination methods [1]. Normal finding obtained from clinical examinations and imaging relieved the female patients with mastalgia, knowing that they do not have cancer [13]. Mastalgia is frequently observed in women aged 30 years [14]. In their study, Johnson et al. found mastalgia mostly prevalent in the age group of 35-55 years [15]. In our study, mastalgia was commonly encountered in the age group of 35 years and younger (55.1\%). Mastalgias are classified into cyclical and non-cyclical. While cyclic mastalgia is experienced as a feeling of fullness in the premenstrual period, noncyclic mastalgia pain is described as having a stabbing or throbbing quality and is often co-existent with fibrocystic disease [16, 17]. The literature revealed the incidence of cyclic pain ranged between $48-81 \%[15,18]$. In another study, cyclic mastalgia was evident in two-thirds of women, whereas noncyclic in one-third [19]. Of the patients in our study, $519(75.8 \%)$ had noncyclic pain, and $166(24.2 \%)$ had cyclic pain. However, despite the statistical numerical difference observed, the pain was not related to the cycle $(\mathrm{p}=0.321)$. Predisposing factors for mastalgia include marital status, age, excessive salt use, inappropriate bra use, employment status, and habits such as consumption of coffee and smoking. The relationship between the pain and marital status (single/married) was significant $(p=0.005)$. Higher pain scores in married women can be explained by the higher responsibility of women in the family and psychological factors such as increased stress related to child care. On the other hand, the relationship between the pain and the state of menopause was not significant $(p=0.468)$. Studies failed to correlate mastalgia with oral contraceptive use or smoking $[15,18]$. Nonetheless, a study conducted in Iraq [20] documented a positive correlation between mastalgia and smoking and hormonal treatment. Present study identified no significant relationship between the pain and hormone use $(p=0.433)$ and smoking $(p=0.796)$. In our study, another risk factor was determined to be the level of education. An enhanced number of applications with the complaints of mastalgia was obtained with a reduced education level. It can be presumed that this increase in the number of applications results from the fear of the unknown. The fact that illiterate or primary school graduates have less access to technological communication tools and information constitutes the basis for this fear.

Research has also proposed the probable relationship of anxiety, depression, and emotional state with mastalgia [18, 21]. Advancement in breast imaging techniques helps to determine the cause of pain. For women with mastalgia symptoms, mammography is conducted in addition to USG in patients older than 40 years and USG only in patients younger than 40 years. USG is also an option for women with dense breast tissue [22]. While all patients in our study underwent breast USG, 144 (21\%) had mammography, and $67(9.8 \%)$ had a biopsy.

Carmichael et al. [23] categorized the breast pain of women as mild (12\%), uncomfortable (55\%), problematic $(22 \%)$, terrible $(8 \%)$, and intolerable (3\%). Research has also demonstrated the effect of breast pain on sleep, sexual life, social, and work/school activities [23, 24]. In our study, we classified breast pain as mild, moderate, and severe. Pain score was in the range of $0-4$ (mild) in $39.7 \%$ of the patients, in the range of 5-7 (moderate) in $35.7 \%$, and in the range of $8-10$ (severe) in $24.5 \%$. Findings from the present study revealed that pain affects day-to-day life, as opined by $25.4 \%$ of patients. Furthermore, 9.3\% stated that pain was intolerable. Ader and Shriver [25] determined the VAS score as 6.5. In our study, all patients had pain, and the mean VAS score was 5.29. Pain resulting from salt consumption is attributed to edema. In our study, salt consumption was considered a risk factor for cyclic mastalgia. Restricted salt intake could successfully reduce this pain. Although the amount of dietary fat consumed, restricted salt and caffeine consumption contribute to the non-pharmacological treatment of mastalgia, their effectiveness is controversial [26]. The use of a bra is another factor affecting mastalgia. It is estimated that a bra without proper fitting is responsible for the onset of mastalgia in $70 \%$ of women. Therefore, the use of a supportive and well-fitting bra by the patient is of utmost importance. A supportive bra is presumed to relieve pain by minimizing the tension of Cooper's ligament and the effect of gravity $[27,28]$. A properly fitted bra is especially beneficial in the case of women with macromastia [29]. One study provided Danazol to one group, and a properly fitted bra was 
recommended to the other group. Symptoms subsided by $58 \%$ (with a drug-related side effect of $42 \%$ ) in the Danazol group, whereas the supportive bra group witnessed an $85 \%$ reduction of the symptoms [27]. Together with a restricted diet in terms of coffee, salt, and fat intake, our study recommended a supportive bra to 456 (66.5\%) patients. Reduction in symptoms was noted in $88.4 \%$ of these patients. The patients believed that wearing bra results in the formation of cancer. This contributed to the most significant cause of not wearing a bra. Patients were given details about this false information.

In our study, vitex agnus-castus was initiated in 181 patients with pain VAS scores of 8 and above, and they were recommended a dietary change and wearing a supportive bra. The patients received vitex agnus-castus for three months. A positive response was derived from 69.6\% (126) of the patients receiving this treatment, stating that they benefited from the treatment. Vitex agnus-castus decreases prolactin level, regulates impaired gonadotropin secretion, providing estrogen-gestagen balance, and resulting in a normal menstrual cycle. Although several trials in the past have successfully used this therapy [30,31], meta-analyses confirmed that the results were similar in reducing pain to those treated with placebo [32,33]. However, our study recorded a positive response in patients with severe pain. Nonetheless, the efficacy of these alternative therapies in managing mastalgia can be validated by monitoring the long-term effectiveness and sustainability after the termination of treatment.

\section{CONCLUSION}

The most prevalent form of malignancy among women worldwide is breast cancer. The main goal is thus to relieve pain and improve the quality of life as well as to exclude the diagnosis of cancer in women with mastalgia. Our study reported that pain is not commonly a sign of cancer. The use of a supportive bra to relieve the pain as well as regular clinical follow-up with dietary alterations are recommended in mastalgia.

As far as prevention and management of mastalgia are concerned, restriction of salt intake, regulation of the diet, and the use of properly-fitted bras could significantly ameliorate the quality of life, and appropriate radiological imaging could eradicate patients' concerns about developing cancer. It also relieves the patients by informing them that wearing a bra does not result in cancer.

\section{LIMITATIONS}

The most vital limitations of this study include that our study is mono-centric, and patients are few. Further studies are thus essential.

\section{Conflict of Interest:}

On behalf of all authors, the corresponding author states that there is no conflict of interest.

\section{Financial Support:}

No financial support was obtained.

\section{REFERENCES}

1. Yıldırım AC, et al. Mastalgia-cancer relationship: a prospective study. J Breast Health. 2015; 11, 88-91.

2. Madlon-Kay J. Meme Kitleleri ve Diğer Meme Hastalıkları In: Mengel MB, Schwiebert LP, editors. Lange Aile Hekimliği Ayaktan Tedavi ve Korunma. Ankara: Güneş Tıp. 2013; pp. 44-47.

3. Ölçücüoğlu E, Yılmaz G. Mastodynia: is imaging necessary in young patients? Ulus Cerrahi Derg. 2013; 29: 17-19.

4. Bilgin $\mathrm{MG}$ et al. Breast cancer frequency among patients who applied to our outpatient department for breast pain. Turk J Fam Prac. 2010; 14: 8-12.

5. Jokich PM et al. Expert Panel on Breast Imaging. ACR appropriateness criteria breast pain. J Am Coll Radiol. 2017; 14: 25-33.

6. Sitruk-Ware R, Sterkers N, Mauvais-Jarvis P. Benign breast disease I: hormonal investigation. Obstet Gynecol. 1997; 53: 457-460.

7. Kumar $\mathrm{S}$ et al. Visual analogue scale for assessing breast nodularity in non-discrete lumpy breasts: the Lucknow-Cardiff breast nodularity scale. Breast.2010; 19: 238-242.

8. Eren $\mathrm{T}$ et al. Factors effecting mastalgia. Breast Care (Basel). 2016; 11: 188-193.

9. Smith RL, Pruthi S, Fitzpatrick LA. Evaluation and Management of Breast Pain. Mayo Clin Proc. 2004; 79: 353-372.

10. Baykal A. Fibrokistik Değişiklikler ve Mastalji. In: Sayek, İ, Özmen. MM editors. Temel Cerrahi El Kitabı. Ankara: Güneș Tıp. 2009; pp. 314-317

11. Balc $1 \mathrm{~N}$ et al. Mastalgia, anxiety and related factors: case-control study. Turk J Fam Prac. 2013; 17: 8-12.

12. Özkan-Onur $\mathrm{G}$ et al. Comparison between radiological and invasive diagnostic modalities in diagnosis of breast cancer. Asian Pac J Cancer Prev. 2015; 16: 4323-4328.

13. Golshan M, Iglehart D. Breast pain, In: Chagpar Anees B., editor. Up To Date. Wellesley. 2015

14. Goyal A, Mansel RE. Mastalgia. In: Jatoi I, Kaufmann M, editors. Management of Breast Diseases. Springer Berlin Heidelberg. 2010; p. 6976.

15. Johnson KM et al. Frequency of mastalgia among women veterans. Association with psychiatric 


\section{Research Article}

Journal of Medical and Surgical Research

JMSR 2021 Vol. VIII, n 1: 984- 989

conditions and unexplained pain syndromes. J Gen Intern Med. 2006; 21: 70-75.

16. Kanat BH et al. Effects of Mastalgia in Young Women on Quality of Life, Depression, and Anxiety Levels. Indian J Surg. 2016; 78: 96-99.

17. Ünal H. Selim Meme Hastalıkları. Ünal G, Ünal H, editörler. Meme Hastalıkları. 1. Baskı. İstanbul: Nobel Tip Kitapevi. 2001; p. 167-188.

18. Ader DN, South-Paul J, Adera, T, Deuster PA. Cyclical mastalgia: prevalence and associated health and behavioral factors. $\mathrm{J}$ Psychosom Obstet Gynaecoly. 2001; 22: 71-76.

19. Cairncross L. Mastalgia: main article. CME. 2010; 28: 504-7.

20. Mohammed AA. Evaluation of mastalgia in patients presented to the breast clinic in Duhok city, Iraq: Cross sectional study. Ann Med Surg (Lond). 2020; 52: 31-35.

21. Colegrave S, Holcombe C, Salmon P. Psychological characteristics of women presenting with breast pain. J Psychosom Res. 2001; 50: 303-307.

22. Yüksekkaya R, Çelikyay F, Voyvoda N, GökdemirYazar Ö. Breast ultrasound findings in patients with mastalgia under the age of fourty. J Breast Health. 2012; 8: 19-22.

23. Carmichael AR, Bashayan O, Nightingale $P$. Objective analyses of mastalgia in breast clinics: is breast pain questionaire a useful tool in a busy breast clinic? Breast. 2006; 15: 498-502.

24. Ader DN, Browne MW. Prevalence and impact of cyclic mastalgia in a United States clinic-based sample. Am J Obstet Gynecol. 1997; 177: 126-132.
25. Ader DN, Shriver CD, Browne MW. Cyclical mastalgia: premenstrual syndrome or recurrent pain disorder? J Psychosom Obstet Gynaecol. 1999; 20: 198-202.

26. Dimagno $\mathrm{MM}$ et al. Guidelines for clinical care: Common breast problems, Universty of Michigan Health system. Available at: http://www.med.umich. edu/linfo/fhp/practiceguides/breast/breast.pdf. Accessed Aug 3. 2017

27. Fındıkçığlu $K$ et al. Does your patient use appropriate brassiere? Bra profile of our female patients. Turk J Plast Surg. 2007; 15: 32-36.

28. Hadi MS. Sports brassiere: is it a solution for mastalgia? The breast journal. 2000; 6: 407-409.

29. Wood K, Cameron M, Fitzgerald K. Breast size, bra fit and thoracic pain in young women: a correlational study. Chiropr Osteopat. 2008; 16: 1.

30. Blommers J, Lange-De Klerk ES, Kuik DJ. Evening primrose oil and fish oil for severe chronic astalgia: A randomized, double-blind, controlled trial. Am J Obstet Gynecol. 2002; 187: 1389-1394.

31. Pashby NL, Mansel RE, Hughes LE. A clinical trial of evening primrose oil in mastalgia. Br J Surg. 1981; 68: 801 .

32. Srivastava A, Mansel RE, Arvinda N. Evidence-based management of mastalgia: a meta-analysis of randomised trials. Breast. 2007; 16: 503-512.

33. Ooi SL, Watts S, McClean R, Pak SC. Vitex AgnusCastus for the Treatment of Cyclic Mastalgia: A Systematic Review and Meta-Analysis. J Womens Health (Larchmt). 2020; 29: 262-278. 